\title{
Associations between the purchase of healthy and fast foods and restrictions to food access: a cross-sectional study in Melbourne, Australia
}

\author{
Cate Burns ${ }^{1, *}$, Rebecca Bentley ${ }^{2}$, Lukar Thornton ${ }^{3}$ and Anne Kavanagh ${ }^{2}$ \\ 'WHO Collaborating Centre for Obesity Prevention, Deakin University, 221 Burwood Highway, Burwood, VIC \\ 3125, Australia: ${ }^{2}$ Centre for Women's Health, Gender and Society, Melbourne School of Population Health, \\ University of Melbourne, Melbourne, Victoria, Australia: ${ }^{3}$ Centre for Physical Activity and Nutrition Research, \\ Deakin University, Melbourne, Victoria, Australia
}

Submitted 9 August 2012: Final revision received 24 August 2013: Accepted 4 September 2013: First published online 28 0ctober 2013

\begin{abstract}
Objective: To examine the associations between financial, physical and transport conditions that may restrict food access (which we define as food security indicators) and the purchase of fast foods and nutritious staples such as bread and milk.

Design: Multilevel logistic and multinomial regression analysis of cross-sectional survey data to assess associations between the three indicators of food insecurity and household food shopping adjusted for sociodemographic and socio-economic variables.

Setting: Random selection of households ( $n$ 3995) from fifty Census Collector Districts in Melbourne, Australia, in 2003.

Subjects: The main food shoppers in each household ( $n$ 2564).

Results: After adjustment for confounders, analysis showed that a greater likelihood of purchasing chain-brand fast food on a weekly basis compared with never was associated with running out of money to buy food (OR $=1 \cdot 59 ; 95 \%$ CI $1 \cdot 08,2 \cdot 34)$ and reporting difficulties lifting groceries $(\mathrm{OR}=1 \cdot 77$; $95 \%$ CI $1 \cdot 23,2 \cdot 54)$. Respondents without regular access to a car to do food shopping were less likely to purchase bread types considered more nutritious than white bread $(\mathrm{OR}=0.75$; $95 \%$ CI $0.59,0.95)$ and milk types considered more nutritious than full-cream milk $(\mathrm{OR}=0 \cdot 62 ; 95 \% \mathrm{CI} 0 \cdot 47,0 \cdot 81)$. The food insecurity indicators were not associated with the purchasing of fruits, vegetables or non-chain fast food.

Conclusions: Householders experiencing financial and physical barriers were more likely to frequently purchase chain fast foods while limited access to a car resulted in a lower likelihood that the nutritious options were purchased for two core food items (bread and milk). Policies and interventions that improve financial access to food and lessen the effect of physical limitations to carrying groceries may reduce the purchasing of fast foods. Further research is required on food sourcing and dietary quality among those with food access restrictions.
\end{abstract}

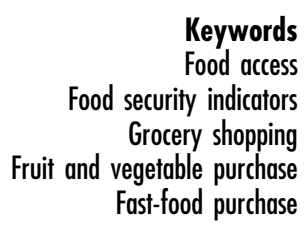

Keywords Food security indicators Grocery shopping Fast-food purchase
A diet that includes a range of nutrient-rich foods and minimises intake of energy-dense, nutrient-poor foods is essential for health ${ }^{(1)}$. Food insecurity arises when individuals lack the financial, physical or means of transport necessary in order to obtain nutritionally adequate and safe foods ${ }^{(2)}$. Prior studies have shown that food insecurity is more common among those experiencing socio-economic disadvantage ${ }^{(3)}$ and is associated with a less healthy dietary profile ${ }^{(4)}$. However, little is known about the independent effects of food insecurity on a range of food purchasing behaviours. An understanding of how multiple food insecurity indicators correlate with food purchasing is an important step towards strengthening strategies that aim to improve Australians' diets and, subsequently, reduce the burden of diet-related disease.

A lack of financial resources is the most common cause of food insecurity. Levels of food insecurity due to lack of money have been shown to be as high as $11 \%$ in the $\mathrm{USA}^{(5)}, 5 \%$ in Australia ${ }^{(6)}$ and $8 \%$ in the $\mathrm{UK}^{(7)}$. The evidence available suggests that food insecurity related to a lack of money is associated with a decline in total household food supplies and of nutritious foods such as dairy, meat, grains, fruit and vegetables ${ }^{(8-10)}$. A second indictor relates to physical limitations, such as the inability to carry groceries. Those experiencing physical limitations may be more prone to seeking foods that are 
convenient to eat on site or easier to carry and thus be less likely to purchase grocery items in bulk. In the USA, physical limitations to food purchasing are concentrated in the elderly ${ }^{(11,12)}$. A third indicator is related to transport as limited car availability for grocery shopping potentially adds a barrier to accessing stores that stock nutritious food options or to transporting groceries home. Previous studies have shown that grocery shopping without a car is associated with difficulty in purchasing sufficient quantities of potentially nutritious groceries ${ }^{(13,14)}$. A UK study found that travel to food outlets by taxi, public transport or private car was associated with higher fibre intakes and higher overall healthy dietary indices in comparison with travel by foot or bicycle ${ }^{(15)}$.

We have previously reported on the prevalence of these three indicators of food insecurity (financial, physical limitations, access to a car) and associations with household characteristics. Our findings showed that each of these indicators was more prevalent among those with lower individual or household socio-economic position, whereas area-level disadvantage was independently associated with difficulty lifting and reduced car access ${ }^{(3)}$.

While financial, transport and physical barriers may restrict purchasing of nutritious foods from a supermarket or similar store, they may also promote the purchase of fast foods or takeaway foods (regarded as foods that can be purchased for immediate consumption from an outlet with limited table service) which are typically less nutritious and sometimes more conveniently obtained. Fast-food consumption has been associated with poor nutrient intakes ${ }^{(16)}$ and adverse health outcomes including obesity ${ }^{(17)}$.

In the present study we advance current evidence on how barriers to food access impact on food purchasing behaviour using data from the Victorian Lifestyle and Neighbourhood Environments Study (VicLANES), a multilevel, cross-sectional study of 2564 households from fifty geographic areas in Melbourne, Australia. Specifically, we examine financial, physical and transport-related indicators of food security and examine their association with the purchase of both healthy foods (e.g. fruits, vegetables and recommended core foods) and fast foods. Investigating how food insecurity is associated with food purchasing patterns is important because of the potential consequences for physical and mental health of those experiencing food insecurity and the economic and social costs to the community at large.

\section{Experimental methods}

\section{Study design}

We analysed data from VicLANES which is a cross-sectional multilevel survey conducted in 2003 in metropolitan Melbourne, Australia. Prior to sampling, all Census Collector Districts (CCD; average size of about 220 dwellings in urban areas) ${ }^{(18)}$ across metropolitan Melbourne were stratified into septiles based on the proportion of households in each CCD with a total household weekly income of less than \$AU 400. Respondents were randomly sampled from a total of fifty CCD from the least ( $n 17$; mean proportion of low-income households $7 \cdot 0 \%$, range $3 \cdot 5-8 \cdot 5 \%$ ), mid ( $n 16$; mean $15 \cdot 3 \%$, range $14 \cdot 4-16 \cdot 7 \%$ ) and most disadvantaged ( $n$ 17; mean $31.4 \%$, range 24.1-59.6\%) septiles. A Food Purchasing Survey was mailed to 3995 households randomly selected from within these CCD with instructions that it be completed by the person who undertook the majority of food shopping. A total of 2564 valid responses were received (64\% response rate). The VicLANES project was approved by the La Trobe University Human Ethics Committee.

\section{Dependent variables}

Further details on the collection and analysis of dietary data are provided elsewhere ${ }^{(3,19,20)}$.

\section{Grocery items (recommended and regular)}

The type or variety of grocery items purchased from grocery stores was examined on the basis of fifteen questions each of which had two or more response options. For example, respondents were asked 'When shopping for your household, what type of milk do you usually buy?' The response options included: 'I do not buy milk', 'extra creamy', 'full cream', 'low-fat/trim', 'skimmed/fat-free', plus 'others'. Multiple responses were permitted for each question. For other food items questions were structured in an identical manner and covered: bread, rice, pasta, noodles, baked beans, tinned fruit, cheese, yoghurt, beef mince, chicken (uncooked), tinned fish, vegetable oil, butter and solid cooking fat. The Australian Guide to Healthy Eating ${ }^{(21)}$ recommends that people purchase and consume a variety of nutritious foods that are relatively high in fibre and low in fat, salt and sugar. Consistent with these guidelines, we classified the grocery foods into recommended (e.g. brown rice) and regular (e.g. white rice). Details of this classification have been reported elsewhere ${ }^{(19)}$ and are provided in the Appendix. Respondents were coded 1 if they purchased the healthy option of a specific food item and 0 if they did not (i.e. purchased the unhealthy option or did not purchase that food at all). For each item, there were a small number of respondents who reported that they never purchased a specified grocery item (ranging from $<1 \%$ for milk to $8 \%$ for tinned fish) and for this item they were classified as did not purchase the healthy food category.

\section{Fruit purchase}

The variety of fruit purchased on a regular basis was examined using the question: 'When shopping for fresh fruit, how often do you buy these types?' The respondent was instructed to include seasonal fruits, but exclude fruit juice, tinned fruit and dried fruit. The question item-set consisted of twenty-two fresh fruits selected from the FFQ 
used in the 1995 Australian National Nutrition Survey ${ }^{(6)}$. For each fruit, respondents were asked to indicate their usual purchasing pattern on the basis of five options: 'never buy', 'rarely buy', 'sometimes buy', 'nearly always buy' and 'always buy'. An index of fruit purchasing was created by summing the number of fruits purchased at least sometimes. For each fruit item respondents reporting that they 'never' or 'rarely' buy were scored 0 and those reporting any of the other three options were scored 1. These items were then summed, with the resultant index score for each respondent indicating the variety of fruits purchased at least sometimes over the course of many shopping episodes. As the variety index was essentially a count measure and non-normally distributed it was categorised into quartiles, with Q1 denoting high variety of fruit purchasing and Q4 low variety as follows: Q1 (15 types or more), Q2 (12 to 14 types), Q3 (9 to 11 types), Q4 (0 to 8 types).

It is important to note that the variety score does not reflect the range of fruits purchased on any particular shopping trip, but rather the types purchased at least sometimes over the course of many shopping trips with no specific time frame given.

\section{Vegetable purchase}

To indicate the variety of vegetables purchased on a regular basis, respondents were asked to indicate how often they purchased twenty-five vegetables including fresh and frozen, but excluding canned or dried vegetables. A variety purchasing index was also categorised in quartiles. The quartile groups were: Q1 (20 or more types), Q2 (17 to 19 types), Q3 (14-16 types), Q4 (0 to 13 types).

\section{Fast-food purchase}

The frequency of fast-food purchase was examined using a question that asked 'In the last month, how many times have you eaten these types of foods at home?' Nine fast-food options were specified: six major fast-food chains (Red Rooster, McDonalds, Kentucky Fried Chicken, Hungry Jacks, Pizza Hut, Subway) and non-chain fast-food outlets (fish ' $n$ ' chips, other fried chicken, other pizza). Frequency of consumption was recorded using the following response categories ('not at all', 'one time', '2-3 times', '4-6 times', '7-10 times' or ' $11+$ times'). The total amount purchased was summed separately for major chain fast foods and non-chain fast foods and categorised as never (0 times over the last month), monthly (1-3 times over the last month) or weekly ( 4 or more times over the last month). Further details of assessment of fast-food purchase are reported elsewhere ${ }^{(20)}$.

\section{Independent variable}

Our three indicators of restricted food access were determined by asking:

1. 'In the last 12 months, were there any times that you ran out of food and could not afford to buy more?'
2. 'Does your health limit the lifting or carrying of groceries?'

3. 'Do you always have access to a car to do your food shopping?'

Each question had a binary (yes/no) response category. Restricted food access was indicated by the answer 'yes' to questions 1 and 2 and 'no' to question 3. The items used to measure the barriers to food access have been used in previous studies. 'In the last 12 months, were there any times that you ran out of food and could not afford to buy more?' is a valid and reliable item used in the measurement of food insecurity in US studies by the US Department of Agriculture ${ }^{(5)}$ and in the National Nutrition Survey in Australia ${ }^{(6)}$. The items used to describe the impact of limitations to lifting or carrying groceries and the impact of access to a car to do food shopping have been tested and used in studies of food access in the $\mathrm{UK}^{(15)}$ and among elderly populations in the USA ${ }^{(11)}$.

\section{Confounders}

Potential confounders, defined at an individual level of the food shopper, included age (18-24 years; $25-34$ years; 35-44 years; 45-54 years; 55-64 years; $\geq 65$ years), country of birth (Australia; other), education (bachelor degree or higher; diploma (associate or undergraduate); vocational; no post-school qualification) and occupation (professional; white collar; blue collar) ${ }^{(22)}$. Householdlevel variables included household composition (single male adult without children; single female adult without children; single adult with a child or children; two or more adults without children; two or more adults with a child or children) and household income (\$AU 20799 or less; \$AU 20 800-36 399; \$AU 36 400-51 999; \$AU 52 000-77999; \$AU 78000 or more). Area-level disadvantage was defined as least, middle and most disadvantaged, and corresponded with the sampling of households from the lowest, middle and highest septiles of area disadvantage. For analysis baseline categories were set for groups that contained the highest number of respondents or were the highest category for socio-economic predictors so that trends could more easily be seen.

\section{Missing data imputation}

A large amount of data was missing for the income variable $(35 \cdot 2 \%)$. As it was considered an important confounding variable, rather than analysing the complete cases only and potentially biasing estimates, missing data were imputed under the MAR (missing at random) assumption. Under this assumption the presence of missing values was modelled as a function of observed variables. Ten data sets with imputed values for missing items on each variable were obtained using the userwritten ICE (imputation by chained equations) command (P Royston) in Stata version 10.0. Models were prefixed by the user-written MIM command (created by JC Galati, 
P Royston and JB Carlin) which allowed for analysis to be undertaken across multiple data sets. Analysing multiple imputed data provides more rigorous estimates of possible effect sizes than other approaches to missing data as standard errors are adjusted for variation in imputed values across each of the data sets ${ }^{(23)}$.

\section{Statistical analysis}

Analyses were conducted in the statistical software package Stata version $10 \cdot 1$. The proportion of the total sample of households purchasing recommended core foods, the quartiles of fruit and vegetable variety and the regularity of consumption of fast foods from chain and non-chain fast-food outlets are described by the three indicators of restricted food access: (i) running out of food and not being able to afford more; (ii) limitations to lifting or carrying groceries; and (iii) reduced access to a car for food shopping. Statistical comparison was made using Pearson's $\chi^{2}$ test.

Logistic regression was used to assess associations between the three indicators of food accessibility and the purchase of groceries with binary outcomes. The Stata (version 10·1) command XTLOGIT was used to model variation in purchasing within and between CCD using the random effects estimator and thereby account for the clustering of people into CCD. Multinomial regression was used to assess these associations for food purchases with multiple outcomes: fruit, vegetables and chain and non-chain fast foods. Multinomial models were estimated using the GLLAMM (generalised linear latent and mixed models) command in Stata. Results from the analysis were presented as odds ratios with $95 \%$ confidence intervals. Models were adjusted for potential confounders including age, household type, country of birth, education, occupation, income and area-level disadvantage. We used an $\alpha$ level of $5 \%$ for statistical significance.

\section{Results}

\section{Descriptive analyses}

Running out of food and not being able to afford more A significantly lower proportion of people who ran out of food (and could not afford to buy more) purchased recommended varieties of bread $(68.4 \% \quad v$. $78.8 \%$, $P<0 \cdot 05)$, milk $(67 \cdot 7 \%, v .79 \cdot 9 \%, P<0 \cdot 05)$ and tinned fish $(67 \cdot 2 \% v \cdot 74 \cdot 0 \%, P<0 \cdot 05)$ compared with people who did not run out of money for food. Additionally, a lower proportion of the financially food insecure group purchased a high variety ( $\geq 15$ types) of fruits $(53.5 \%$ v. $40 \cdot 7 \%$, $P<0 \cdot 05$ ) and vegetables ( $\geq 20$ types; $46 \cdot 6 \%$ v. $42 \cdot 0 \%$, $P<0 \cdot 05)$ compared with their counterparts (Table 1 ).

Limitations to lifting or carrying groceries A significantly lower proportion of householders who experienced difficulty in lifting purchased the recommended variety of tinned fish compared with people who did not report this problem $(69 \cdot 3 \% v \cdot 74 \cdot 4 \%, P<0 \cdot 05$; Table 1$)$. No other differences were observed for purchase of groceries or fruit and vegetables.

Reduced access to a car for food shopping

Compared with people with who did not report limited car access, a significantly lower proportion of householders with limited car access for grocery shopping purchased the recommended options for cheese $(66.8 \%$ v. $60.6 \%, P<0.05)$, rice $(14.7 \%$ v. $11.3 \%, P<0.05)$, bread (79.4\% v. 69.7\%, $P<0 \cdot 05)$, milk $(81 \cdot 1 \% v \cdot 65 \cdot 7 \%$, $P<0.05)$, chicken $(86.9 \% v \cdot 77 \cdot 1 \%, P<0.05)$ and tinned fish $(75.0 \% v \cdot 64.5 \%, P<0.05)$ and purchased a lower variety of fruit $(P=0 \cdot 05$; Table 1$)$.

\section{Regression analyses (adjusted for confounders)}

Running out of food and not being able to afford more Households that had run out of food and could not afford more were significantly more likely to purchase chain fast foods on a weekly basis (OR $=1 \cdot 59$; $95 \%$ CI 1·08, 2.34). No associations were found for grocery items, fruits, vegetables and non-chain fast foods (Table 2).

\section{Limitations to lifting or carrying groceries}

Households in which the main grocery shopper had difficulty lifting were significantly more likely to purchase chain fast foods on a weekly basis (OR $=1 \cdot 77$; 95\% CI $1 \cdot 23,2 \cdot 54$ ). There was weak evidence (not statistically significant at the $5 \%$ level of significance) to suggest that these households were also more likely to purchase chain fast foods on a monthly basis (OR $=1 \cdot 23$; $95 \%$ CI $0.98,1.54)$ and non-chain fast foods on a weekly basis $(\mathrm{OR}=1 \cdot 45$; $95 \% \mathrm{CI} 0 \cdot 99,2 \cdot 13)$. Again, no associations were detected for grocery items, fruits or vegetables (Table 2).

\section{Reduced access to a car for food shopping}

Households without regular access to a car for grocery shopping were significantly less likely to purchase more nutritious options for both milk (OR $=0.75 ; 95 \%$ CI 0.59 , $0.95)$ and bread $(\mathrm{OR}=0.62 ; 95 \% \mathrm{CI} 0 \cdot 47,0 \cdot 81)$. There was some evidence that they are also more likely to purchase a lower variety of fruit; however, again this difference was not statistically significant $(\mathrm{OR}=1 \cdot 49$; 95\% CI 0.99, 2.25; Table 2).

\section{Discussion}

The current study is one of the first to examine the association between food security and food purchasing. Some evidence was found that two indicators of food insecurity (financial and physical restrictions) were associated with more frequent fast-food purchasing. Several factors 
Table 1 Food purchasing by food insecurity indicators: the Victorian Lifestyle and Neighbourhood Environments Study, Melbourne, Australia, 2003

\begin{tabular}{|c|c|c|c|c|c|c|c|c|}
\hline & \multirow{2}{*}{\multicolumn{2}{|c|}{ Total }} & \multicolumn{2}{|c|}{ Can't afford food ( $n$ 2564)† } & \multicolumn{2}{|c|}{ Difficulty lifting $(n$ 2564)‡ } & \multicolumn{2}{|c|}{ Limited car access $(n$ 2564)§ } \\
\hline & & & \multirow{2}{*}{$\begin{array}{c}\text { No } \\
\frac{(n 2358 ; 91.9 \%)}{\%}\end{array}$} & \multirow{2}{*}{$\begin{array}{c}\text { Yes } \\
\frac{(n 206 ; 8 \cdot 1 \%)}{\%}\end{array}$} & \multirow{2}{*}{$\begin{array}{c}\text { No } \\
\frac{(n 2077 ; 80.9 \%)}{\%}\end{array}$} & \multirow{2}{*}{$\begin{array}{c}\text { Yes } \\
\frac{(n 487 ; 19 \cdot 1 \%)}{\%}\end{array}$} & \multirow{2}{*}{$\begin{array}{c}\text { No } \\
\frac{(n 2182 ; 85 \cdot 0 \%)}{\%}\end{array}$} & \multirow{2}{*}{$\begin{array}{c}\text { Yes } \\
(n 382 ; 15.0 \% \\
\%\end{array}$} \\
\hline & $n$ & $\%$ & & & & & & \\
\hline \multicolumn{9}{|c|}{ Recommended option } \\
\hline Pasta & 226 & $8 \cdot 9$ & $8 \cdot 8$ & $9 \cdot 5$ & $9 \cdot 2$ & $7 \cdot 5$ & $8 \cdot 7$ & $9 \cdot 9$ \\
\hline Cheese & 1682 & $65 \cdot 9$ & $65 \cdot 6$ & $68 \cdot 6$ & $65 \cdot 7$ & $66 \cdot 3$ & $66 \cdot 8$ & $60 \cdot 6^{*}$ \\
\hline Rice & 362 & $14 \cdot 2$ & $14 \cdot 2$ & $13 \cdot 2$ & $14 \cdot 5$ & $12 \cdot 9$ & $14 \cdot 7$ & $11 \cdot 3^{*}$ \\
\hline Bread & 1991 & $78 \cdot 0$ & $78 \cdot 8$ & $68 \cdot 4^{*}$ & $78 \cdot 1$ & $77 \cdot 5$ & $79 \cdot 4$ & $69 \cdot 7^{*}$ \\
\hline Milk & 2013 & $78 \cdot 9$ & $79 \cdot 9$ & $67 \cdot 7^{\star}$ & $79 \cdot 5$ & $76 \cdot 1$ & $81 \cdot 1$ & $65 \cdot 7^{*}$ \\
\hline Chicken & 2182 & $85 \cdot 5$ & $85 \cdot 8$ & $81 \cdot 3$ & $85 \cdot 3$ & $86 \cdot 1$ & 86.9 & $77 \cdot 1^{*}$ \\
\hline Tinned fish & 1817 & $73 \cdot 4$ & $74 \cdot 0$ & $67 \cdot 2^{*}$ & $74 \cdot 4$ & $69 \cdot 3^{*}$ & $75 \cdot 0$ & $64 \cdot 5^{\star}$ \\
\hline \multicolumn{9}{|l|}{ Fruit } \\
\hline $0-8$ types & 257 & $12 \cdot 5$ & $12 \cdot 0$ & $18 \cdot 3$ & $12 \cdot 7$ & $11 \cdot 4$ & $11 \cdot 4$ & $19 \cdot 2$ \\
\hline $9-11$ types & 300 & $14 \cdot 6$ & $14 \cdot 5$ & $16 \cdot 3$ & $14 \cdot 5$ & $15 \cdot 0$ & $14 \cdot 4$ & $16 \cdot 0$ \\
\hline $12-14$ types & 419 & $20 \cdot 4$ & $20 \cdot 0$ & $24 \cdot 7$ & $19 \cdot 5$ & $25 \cdot 1$ & $20 \cdot 0$ & $23 \cdot 1$ \\
\hline$\geq 15$ types & 1077 & $52 \cdot 5$ & $53 \cdot 5$ & $40 \cdot 7^{\star}$ & $53 \cdot 3$ & $48 \cdot 4$ & $54 \cdot 2$ & $41 \cdot 7^{*}$ \\
\hline \multicolumn{9}{|l|}{ Vegetables } \\
\hline $0-13$ types & 232 & $10 \cdot 8$ & $10 \cdot 5$ & $14 \cdot 1$ & $11 \cdot 0$ & $9 \cdot 6$ & $10 \cdot 3$ & $13 \cdot 6$ \\
\hline $14-16$ types & 375 & $17 \cdot 4$ & $16 \cdot 8$ & $24 \cdot 4$ & $17 \cdot 5$ & $16 \cdot 8$ & $17 \cdot 5$ & $17 \cdot 1$ \\
\hline $17-19$ types & 551 & $25 \cdot 6$ & $26 \cdot 0$ & $19 \cdot 5$ & $25 \cdot 7$ & $24 \cdot 9$ & $25 \cdot 3$ & $27 \cdot 3$ \\
\hline$\geq 20$ types & 997 & $46 \cdot 3$ & $46 \cdot 6$ & $42 \cdot 0^{*}$ & $45 \cdot 8$ & $48 \cdot 6$ & $46 \cdot 9$ & $42 \cdot 0$ \\
\hline \multicolumn{9}{|l|}{ Chain fast foods } \\
\hline Never & 1336 & $52 \cdot 1$ & $53 \cdot 1$ & $41 \cdot 1$ & $52 \cdot 5$ & $50 \cdot 8$ & $52 \cdot 4$ & $50 \cdot 6$ \\
\hline Monthly & 900 & $35 \cdot 1$ & 34.9 & $34 \cdot 1$ & $35 \cdot 2$ & $33 \cdot 2$ & $34 \cdot 9$ & $34 \cdot 4$ \\
\hline Weekly & 328 & $12 \cdot 8$ & $12 \cdot 0$ & $24 \cdot 8$ & $12 \cdot 3$ & $16 \cdot 0$ & $12 \cdot 7$ & $15 \cdot 0$ \\
\hline \multicolumn{9}{|c|}{ Non-chain fast foods } \\
\hline Never & 860 & 33.5 & 33.9 & 28.9 & $32 \cdot 6$ & $37 \cdot 3$ & $32 \cdot 5$ & $39 \cdot 4$ \\
\hline Monthly & 1415 & $55 \cdot 2$ & $55 \cdot 4$ & $54 \cdot 1$ & $56 \cdot 5$ & $49 \cdot 8$ & $56 \cdot 9$ & $46 \cdot 1$ \\
\hline Weekly & 289 & $11 \cdot 3$ & $10 \cdot 7$ & $17 \cdot 0$ & $10 \cdot 8$ & $12 \cdot 9$ & $10 \cdot 7$ & $14 \cdot 4$ \\
\hline
\end{tabular}

*Indicates a significant difference compared with the 'no' group at the 0.05 level, value determined by Pearson's $\chi^{2}$ test. t'In the last 12 months, were there times that you ran out of food and could not afford to buy more?'

$\ddagger$ 'Does your health limit the lifting or carrying of groceries?'

$\S$ 'Do you always have access to a car to do your food shopping?'

may explain the association between financial restrictions and fast-food purchasing including its perceived cheapness $^{(24,25)}$, people's access to facilities to prepare foods ${ }^{(26)}$ and chain fast-food outlets offering disadvantaged groups a place to feel socially included ${ }^{(27)}$. Householders with physical limitations to lifting may be more reliant on fast foods because they cannot carry groceries to or prepare food at home easily.

Conversely, the current study provides no evidence of an association between financial food insecurity and the purchase of fruits and vegetables and nutritionally recommended foods. This is in contrast with previous studies ${ }^{(8-10)}$ which found that the purchase of recommended healthy foods declined with increasing food insecurity due to lack of money. This could be due to differences in the cost of these foods or the size of government allowances across the countries or cities in which these studies were conducted. Additionally, with regard to difficulty in lifting, no relationship was found with the purchase of healthy foods; a finding that is consistent with previous research ${ }^{(15)}$. This may be because householders with physical limitations are supported by relatives or friends or services in the community that ensure their access to nutritious food ${ }^{(28)}$.
Limited evidence was also found that reduced vehicle access may be associated with the less frequent purchasing of some nutritious food items. A possible explanation for this is that the lack of a car to do food shopping may limit a household's access to major supermarkets, making householders more reliant on nearby smaller grocery stores which have a more limited range of foods. This is supported by other studies which indicate that lack of a car affects access to major supermarkets ${ }^{(13)}$. Our findings in relation to access to a car and less healthy food purchasing behaviour are consistent with a UK study which found an association between the availability of transport to shop and the nutritional quality of food purchases ${ }^{(15)}$.

The current study's strengths included the use of a large population-based sample, the comprehensive range of dietary measures surveyed including healthy and less healthy options, the inclusion of three different types of food insecurity in one study, the adjustment for a number of potential confounders which are known to be predictive of healthy ${ }^{(29)}$ and fast-food consumption $^{(20)}$, and having both chain and non-chain fast-food outcomes which expands the scope of the fast-food outlets studied. 
Table 2 Regression analyses of food purchasingt among those experiencing food insecurity: the Victorian Lifestyle and Neighbourhood Environments Study, Melbourne, Australia, 2003

\begin{tabular}{|c|c|c|c|c|c|c|}
\hline & \multicolumn{2}{|c|}{ Can't afford food } & \multicolumn{2}{|c|}{ Difficulty lifting } & \multicolumn{2}{|c|}{ Limited car access } \\
\hline & OR & $95 \% \mathrm{Cl}$ & OR & $95 \% \mathrm{Cl}$ & OR & $95 \% \mathrm{Cl}$ \\
\hline \multicolumn{7}{|c|}{ Recommended option } \\
\hline Pasta & $1 \cdot 16$ & $0 \cdot 62,2 \cdot 19$ & 0.81 & $0 \cdot 54,1 \cdot 22$ & $1 \cdot 11$ & $0.75,1.65$ \\
\hline Cheese & $1 \cdot 36$ & $0.99,1 \cdot 87$ & $1 \cdot 04$ & $0 \cdot 80,1 \cdot 36$ & $0 \cdot 87$ & $0 \cdot 67,1 \cdot 12$ \\
\hline Rice & 1.01 & $0.66,1.55$ & 0.96 & $0 \cdot 72,1 \cdot 28$ & 0.81 & $0.51,1.26$ \\
\hline Bread & $0 \cdot 76$ & $0.55,1.05$ & 0.99 & $0 \cdot 73,1 \cdot 38$ & 0.75 & $0.59,0.95^{\star}$ \\
\hline Milk & 0.78 & $0.56,1.09$ & 1.00 & $0 \cdot 74,1 \cdot 36$ & 0.62 & $0.47,0.81^{*}$ \\
\hline Chicken & $1 \cdot 17$ & $0.83,1.66$ & $1 \cdot 34$ & $0.93,1.95$ & 0.78 & $0.57,1.07$ \\
\hline Tinned fish & 0.93 & $0 \cdot 66,1 \cdot 32$ & 0.96 & $0 \cdot 72,1 \cdot 29$ & $0 \cdot 88$ & $0 \cdot 71,1 \cdot 09$ \\
\hline \multicolumn{7}{|l|}{ Fruit } \\
\hline $0-8$ types & $1 \cdot 31$ & $0 \cdot 77,2 \cdot 25$ & $1 \cdot 13$ & $0 \cdot 75,1 \cdot 70$ & $1 \cdot 49$ & $0.99,2 \cdot 25$ \\
\hline $9-11$ types & $1 \cdot 11$ & $0.67,1.84$ & $1 \cdot 23$ & $0.79,1.94$ & 1.07 & $0.73,1.56$ \\
\hline $12-14$ types & $1 \cdot 18$ & $0.79,1.76$ & $1 \cdot 32$ & $0.94,1 \cdot 87$ & $1 \cdot 20$ & $0.83,1 \cdot 71$ \\
\hline$\geq 15$ types & $1 \cdot 00$ & - & $1 \cdot 00$ & - & $1 \cdot 00$ & - \\
\hline \multicolumn{7}{|l|}{ Vegetables } \\
\hline $0-13$ types & 0.92 & $0 \cdot 50,1 \cdot 71$ & 0.92 & $0 \cdot 56,1 \cdot 50$ & 0.91 & $0 \cdot 60,1 \cdot 38$ \\
\hline 14-16 types & $1 \cdot 21$ & $0.76,1.92$ & 1.03 & $0 \cdot 70,1 \cdot 51$ & 0.80 & $0.53,1.20$ \\
\hline 17-19 types & 0.67 & $0.42,1.07$ & 0.99 & $0 \cdot 74,1 \cdot 33$ & 0.97 & $0.68,1.39$ \\
\hline$\geq 20$ types & $1 \cdot 00$ & - & $1 \cdot 00$ & - & $1 \cdot 00$ & - \\
\hline \multicolumn{7}{|l|}{ Chain fast foods } \\
\hline Never & $1 \cdot 00$ & - & $1 \cdot 00$ & - & $1 \cdot 00$ & - \\
\hline Monthly & 0.97 & $0 \cdot 70,1 \cdot 37$ & $1 \cdot 23$ & $0.98,1.54$ & $1 \cdot 04$ & $0 \cdot 77,1 \cdot 39$ \\
\hline Weekly & 1.59 & $1 \cdot 08,2 \cdot 34^{\star}$ & $1 \cdot 77$ & $1 \cdot 23,2 \cdot 54^{*}$ & $1 \cdot 01$ & $0.69,1.49$ \\
\hline \multicolumn{7}{|c|}{ Non-chain fast foods } \\
\hline Never & 1.00 & - & 1.00 & - & 1.00 & - \\
\hline Monthly & 1.04 & $0.68,1.59$ & $1 \cdot 07$ & $0 \cdot 81,1 \cdot 42$ & 0.82 & $0 \cdot 63,1 \cdot 07$ \\
\hline Weekly & $1 \cdot 31$ & $0.77,2 \cdot 22$ & $1 \cdot 45$ & $0.99,2 \cdot 13$ & $1 \cdot 20$ & $0.82,1 \cdot 76$ \\
\hline
\end{tabular}

*Indicates that odds ratio and $95 \%$ confidence interval are significant at the 0.05 level.

tAdjusted for age, household type, country of birth, education, occupation, income and area-level disadvantage.

It is also recognised that the study included some limitations. While we were able to examine multiple indicators of food security, these questions were answered using single-item questions. Other studies, usually of financial food insecurity, use multi-item measures; for example, the US Department of Agriculture's Food Security Scale has eighteen items ${ }^{(5)}$. The latter survey provides a more reliable and robust assessment of food insecurity with greater sensitivity and specificity than single-item measures. While a response rate of $59 \%$ is good for surveys there is still potential for selection bias due to non-response because the association between food security and food purchasing is different for nonrespondents and respondents. As reported previously ${ }^{(20)}$, the response rates were lowest in the most disadvantaged areas. Because the respondents were the person who did the majority of the food shopping (and not a random household member) we were unable to enumerate the relevant study population (e.g. in terms of variables such as ethnicity). Another potential limitation is that respondents may tend to report socially desirable responses to questions about food purchasing which could bias our effect estimates. If the misreporting differs between those who are food insecure and those who are not, this will lead to systematic bias that could bias estimates away from the null. While those who reported purchasing the unhealthy variety of the core items and those who did not purchase the item at all were included in the same category of the exposure variable, this is not likely to impact our findings because (i) the percentage of people who did not purchase common items was low and (ii) this percentage did not vary across food insecurity indicators. Finally, missing data on income were imputed because $35 \%$ of the survey participants did not report their income and not doing this could introduce potential bias compared with complete case analyses.

\section{Conclusion}

The current study provides evidence that restrictions to food access because of lack of money and physical limitations to lifting groceries are associated with increased likelihood of purchasing of fast foods regularly. Therefore these restrictions may have a detrimental effect on the nutritional quality of diets for these groups. Our findings suggest that policies and interventions that reduce levels of financial insecurity and access to food due to physical limitations may reduce the purchasing of fast foods.

\section{Acknowledgements}

Sources of funding: C.B. was supported with a Public Health Research Fellowship from VicHealth. R.B. was supported by a National Health and Medical Research Council Capacity Building Grant (ID 324724). L.T. was 
supported by a National Health and Medical Research Council Capacity Grant (ID 425845). VicHealth provided the funding for the VicLANES study (2001-0436). The funders of the study, VicHealth and the National Health and Medical Research Council, did not make any contribution to the study design, analyses or writing of this article. Conflict of interest: None to declare. Authors contributions: C.B. was responsible for the study design, text drafting and editing; R.B. was responsible for data analyses and interpretation, text drafting and editing; L.T. was responsible for data analyses and interpretation, text drafting and editing; A.K. was responsible for study design, text drafting and editing. Acknowledgements: The authors wish to thank Professors David Crawford, Gavin Turrell and Damian Jolley, who were chief investigators on the VicLANES project, and Tania King and Emma Rawlings, who led the field work for the study.

\section{References}

1. Wahlqvist ML (2002) Food and Nutrition, 2nd ed. Sydney: Allen and Unwin.

2. Anderson $S$ (1990) Core indictors of nutritional state for difficult-to-sample populations. J Nutr 120, 1557-1600.

3. Burns C, Bentley R, Thornton L et al. (2011) Reduced food acess due to a lack of money, inability to lift and lack of access to a car for food shopping: a multilevel study in Melbourne, Victoria. Public Health Nutr 14, 1017-1023.

4. Tarasuk VS \& Beaton GH (1999) Women's dietary intakes in the context of household food insecurity. J Nutr 129, 672-679.

5. Nord M, Andrews MS \& Carlson SJ (2008) Household Food Security in the United States, 2007. Washington, DC: US Department of Agriculture, Economic Research Service.

6. Australian Bureau of Statistics (1998) National Nutrition Survey: Nutrient Intakes and Physical Measurements, Australia, 1995. Canberra: ABS.

7. Dowler E (2001) Inequalities in diet and physical activity in Europe. Public Health Nutr 4, 701-710.

8. Kendall A, Olson CM \& Frongillo EA (1996) Relationship of hunger and food insecurity to food availability and consumption. J Am Diet Assoc 96, 1019-1024.

9. Dachner N, Ricciuto L, Kirkpatrick SI et al. (2003) Food purchasing and food insecurity among low-income families in Toronto. Can J Diet Pract Res 71, 50-56.

10. Dibsdall L, Lambert N, Bobbin R et al. (2003) Low-income consumers' attitudes and behaviour towards access, availability and motivation to eat fruit and vegetables. Public Health Nutr 6, 159-168.

11. Wolfe WS, Frongillo EA \& Valois P (2003) Understanding the experience of food insecurity by elders suggests ways to improve its measurement. J Nutr 133, 2762-2769.
12. Sharkey JR (2008) Diet and health outcomes in vulnerable populations. Ann N Y Acad Sci 1136, 210-217.

13. Lang T \& Caraher M (1998) Access to healthy foods: part II. Food poverty and shopping deserts: what are the implications for health promotion policy and practice? Health Educ J 57, 202-211.

14. White M (2007) Food access and obesity. Obes Rev 8, 99-107.

15. White M, Bunting J, Raybould S et al. (2004) Do Food Deserts Exist? A Multi-Level, Geographical Analysis of the Relationship Between Retail Food Access, Socio-Economic Position and Dietary Intake. London: Food Standards Agency.

16. Burns C, Jackson M, Gibbons C et al. (2002) Foods prepared outside the home: association with selected nutrients and body mass index in adult Australians. Public Health Nutr 5, 441-448.

17. Prentice AM \& Jebb SA (2003) Fast foods, energy density and obesity: a possible mechanistic link. Obes Rev 4, 187-194.

18. Australian Bureau of Statistics (2001) Australian Standard Geographical Classification (ASGC). Canberra: ABS.

19. Turrell G, Bentley R, Thomas LR et al. (2009) A multilevel study of area socio-economic status and food purchasing behaviour. Public Health Nutr 12, 2074-2083.

20. Thornton LE, Bentley RJ \& Kavanagh AM (2011) Individual and area-level socio-economic associations with fast food purchasing. J Epidemiol Community Health 65 , 873-880.

21. Kellett E, Smith A \& Schmelaib Y (1998) The Australian Guide to Healthy Eating. Prepared for Australian Government, Department of Health and Ageing. Canberra: Commonwealth of Australia.

22. Australian Bureau of Statistics (1997) Australian Standard Classification of Occupations: Dictionary, 2nd ed. Catalogue no. 1220.0. Canberra: Australian Government Publishing Service.

23. Klebanoff MA \& Cole SR (2008) Use of multiple imputation in the epidemiologic literature. Am J Epidemiol 168, 355-357.

24. Drewnowski A \& Spector SE (2004) Poverty and obesity: the role of energy density and energy cost. Am J Clin Nutr 79, 6-16.

25. Cameron-Smith D, Bilsborough SA \& Crowe T (2002) Upsizing Australia's waistline: the dangers of 'meal deals'. Med J Aust 177, 686.

26. Dachner N \& Tarasuk V (2002) Homeless 'squeegee kids': food insecurity and daily survival. Soc Sci Med 54, 1039-1049.

27. Doljanin K \& Olaris K (2004) Subsided café meals program: more than 'just a cheap meal'. Aust J Primary Health 10, 1-7.

28. Coveney J \& O'Dwyer LA (2009) Effects of mobility and location on food access. Health Place 15, 45-55.

29. Turrell G, Hewitt B, Patterson C et al. (2002) Socioeconomic differences in food purchasing behaviour and suggested implications for diet-related health promotion. J Hum Nutr Diet 15, 355-364. 
Appendix

\section{Classification of grocery food types into 'recommended' and 'regular' categories}

\begin{tabular}{|c|c|c|}
\hline Food type & Recommended & Regular \\
\hline Bread & $\begin{array}{l}\text { Wholemeal, multigrain, white high in fibre, rye, soya } \\
\text { and linseed }\end{array}$ & White \\
\hline Rice & Wholemeal or brown & $\begin{array}{l}\text { Plain white and other white rice (basmati, jasmine, } \\
\text { Arborio) }\end{array}$ \\
\hline Pasta & Wholemeal or brown & Other pasta (white, egg, herb) \\
\hline Noodles & Wholemeal or brown & Other noodles (white, egg, spinach) \\
\hline Baked beans & Salt-reduced or unsalted & Regular salt \\
\hline Tinned fruit & In natural juice & In syrup \\
\hline Cheese & Reduced-fat (25\% less fat), low-fat ( $<10 \%$ fat) & Full-fat \\
\hline Milk & $\begin{array}{l}\text { Reduced-fat, low-fat, high-Ca skimmed, high-Fe, } \\
\text { high-protein, reduced-lactose, no cholesterol, } \\
\text { soya or soya and linseed (skimmed) }\end{array}$ & $\begin{array}{l}\text { Extra creamy, full-cream, soya or soya and linseed } \\
\text { (full-cream) }\end{array}$ \\
\hline Yoghurt & Low-fat (plain and fruit) & Full-fat (plain and fruit) \\
\hline Beef mince & Lean (trim or premium) & Regular (choice or fine grade) \\
\hline Chicken (uncooked) & Without skin, with skin (and remove before eating) & With skin (and eat skin) \\
\hline Tinned fish & In water or spring water & In oil or brine \\
\hline Vegetable oil & $\begin{array}{l}\text { Canola, sunflower, safflower, olive, corn, soyabean, } \\
\text { peanut or sesame, grape seed or macadamia }\end{array}$ & Blended oils, coconut oil, palm oil \\
\hline Butter & Salt-reduced, unsalted & Regular salt \\
\hline Cooking oil & Cooking margarine, solidified oil & $\begin{array}{l}\text { Solid animal fat (lard, beef dripping), vegetable } \\
\text { shortening, ghee or butter (and use for cooking) }\end{array}$ \\
\hline
\end{tabular}

